\title{
П. Курхинен
}

\section{ЧЕЛОВЕЧЕСКОЕ ДОСТОИНСТВО, ЭТИЧЕСКИЙ СОЦИАЛИЗМ И СОВЕТСКАЯ ЭТИКА}

\begin{abstract}
Цель статьи - очертить существенное различие этического сочиализма от радикального, или левого, социализма, т.е., не в политическом, а в этическом плане. Выяснить, почему так актуален морально-правовой аспект в философии этического социализма и как категорический императив Канта может обогатить диалектический материализм. Показать, почему изменять сочиальную действительность лучше мирным путем, а не мировыми революииями, сохраняя при этом человеческое достоинство как иенность саму по себе. $К$ этому стремились и советские этики, в частности Олег Григорьевич Дробницкий

Ключевые слова: этический социализм, морально-правовой аспект философии, сочиальная практика, категорический императив и человеческое достоинство, вещь в себе
\end{abstract}

\section{I. Неокантианство и марксизм}

Совершенно случайно, листая статьи, касающиеся этического социализма, я наткнулся на интересную статью Веса Ойттинена, известного финского философа и специалиста по советской философии, имеющего ряд публикаций на мировом уровне. Статья касалась проведенного им семинара по Бернштейну и другим представителям этического «неокантианского» социализма, а также критики неокантианства «слева» или умеренного (Каутский) и ортодоксального социализма, а именно Мерингом, Плехановым, Лениным. Представленная на семинаре статья называлась «Бернштейн и тень Канта над рабочим движением».

«Понимание социализма левыми все больше становилось "классовым" и, с другой стороны, технократичным (в социализме не пытались осуществить никакой ценностный мир, а его осуществление было делом инженеров). Эти, так сказать, оплошности пытались залатать при перестройке Горбачева, когда признали «общегуманные ценности», но, к сожалению, изменение курса пришло слишком поздно», - замечает Веса [1. С. 1] Под этим Ойттинен, очевидно, подразумевает развал СССР.

Надо заметить, что у марксизма II Интернационала отсутствовала «своя» философия и философские проблемы выступали во второстепенной роли, и это было весьма в научно-позитивистской окраске. Далее все это прибрело форму научного коммунизма. Исторический материализм понимался как дарвинистское учение о развитии, как ее вариант на социальном уровне. Научный социализм (коммунизм) учил, что общество развивается из капитализма в социализм «естественноисторической необходимостью» так же, как и живые существа переходят на более высокий уровень развития благодаря механизму естественного отбора. Все моральные проблемы решались, обра- 
щаясь к «интересам» и их применению. На практике марксизм II Интернационала не очень далеко отошел от материализма Просвещения Гельвеция, Гольбаха и т. д. и их учения о «правильно понятых интересах» как ключе к решению всех проблем.

В принципе, в этом нет ничего удивительно, так как французский писатель Чарльз Раппорт уже в 1900 г. в своем произведении Le matérialisme de Marx et l'idéalisme de Kant о марксистской теории писал: «Беря точнее, в марксизме этого нет совсем (рассуждений о морали). Маркс стремился объяснить источники моральных идей, но ничего при этом не упомянул о внутренней ценности этих идей. Он нигде не рассуждает о том, что индивидов можно рассматривать в качестве моральных существ. Но его исторический анализ морали оставляет место для надежды. Исходя из Маркса, общезначимой (универсальной) морали не существует. У каждого класса, который предопределен экономически, - своя мораль. У каждого периода времени, который тоже экономически предопределен, - своя мораль» [1. С. 4].

Мораль, таким образом, не рассматривали в качестве автономной силы, регулирующей его деятельность, а ее заменили научным анализом. Люди, таким образом, поступают не под влиянием каких-либо моральных норм, а потому, как их материальные интересы (которые могут быть подсознательными, но проявляются «по-научному» как потаенные мотивы) «приказывают» так поступать.

Такой вульгарный редукционизм не мог удовлетворять далее никого, и поэтому в принципе нет ничего удивительного, что «правые» (этические) социалисты II Интернационала ухватились именно за эту слабую часть теории левых (ордоксальных марксистов). Начало положил яркий представитель Марбургской школы неокантианства Герман Коген (1896), провозгласив в послесловии к пятому изданию произведения F.A. Langen Geschichtedes Materialismus: «Социализм правомочен, когда он основывается на этике идеализма. И этика идеализма обосновывала это [...] Кант, как идеальный политик, апеллировал именно к Платону, и он убедительно обосновал истинность и осуществимость республики, которая оставалась грезами всех утопий. Кант - истинный и действительный зачинатель социализма» [1. C. 7].

Кроме Ланге, смешивающего социализм с дарвинизмом, и Когена, одним из значительных «этических социалистов» был Эдуард Бернштейн (18501932) - немецкий социал-демократ. В своих статьях под общим заголовком «Проблемы социализма» (1896-1898) он подверг ревизии основные положения марксизма в области философии, политической экономии, теории научного социализма. Провозгласив лозунг «Назад к Канту», Бернштейн отказался от последовательно материалистического решения основного вопроса философии; отождествлял марксистскую диалектику с гегельянской. Бернштейн отрицал саму возможность научного социализма. Социализм, по Бернштейну, является лишь морально-этическим идеалом. Отвергая идею диктатуры пролетариата, он проповедовал теорию затухания классовой борьбы и признавал единственной задачей рабочего класса борьбу за мелкие реформы в рамках капитализма. Отсюда его известная фраза: «Конечная цель - ничто, движение - все. Еще в 1897-1898 Бернштейн заявил в Die Neue 
Zeitissa, что, по его мнению, «Обратно к Канту!» подходит, по крайней меpe, до какой-то степени. На следующий, 1899, год, выходит известное произведение «Предпосылки сочиализма и задачи социал-демократии», в котором, так сказать, были обоснованы цели ревизионистского крыла II Интернационала [1. С. 4].

Своим известным выражением «Цель социализма ничто, движение все» Бернштейн на самом деле, лишь хотел показать, что социал-демократам надо прекратить обосновывать свои действия на неизбежности, «на естественной необходимости» и уничтожении капитализма. В эту картину хорошо вписывается то, что Бернштейн в других связях противился «натурализму» в науке и искусстве, в которых имеет значение только лишь объективнылй агент; значение индивида, как самостоятельно принимающего свои решения, также пропадает в небытии [1. С. 3] (курсив наш. - П.К.).

В любом случае, мышление, основанное на учении Канта, давало некоторую независимость этическому моменту, а также свободу субъективному агенту действий в истории, в отличие от поддерживаемого левыми и умеренными (Каутским) детерминизма.

По мнению многих интерпретаторов и комментаторов «этического социализма», в том числе и Ойттинена, философия неокантианства совсем не представляла «настоящего» Канта, и ее можно назвать неким соответствием английскому и французскому позитивизму XXI века. Неокантианство лишь взяло у Канта отобранные куски и отказалось от слишком радикальных и материалистических тенденций. Ding an sich «Вещь в себе», которая, исходя из Канта, является первопричиной и основой всех наших чувств, вела, по мнению неокантианцев, к дуализму материальных вещей и субъективной чувственности. Они (неокантианцы) «упростили» учение Канта, уничтожив вещь в себе. В конечном итоге остался лишь субъективный опыт - без объектов, которые на него воздействовали. Неокантианство als ob (как бы) заложило тенденции к субъективному идеализму, который, по нашему мнению, привел, в свою очередь, к прагматизму и т. д.

Еще одним значительным упущением неокантианцев было то, что, по Канту, человеческая свобода у субъекта сама является моральным регулятором законов, а Коген и Штамлер вместо этого обосновывали основу морали в юридических отношениях. Так же как математика является образцом и основой для естественных наук, так и юриспруденция - это основа для этики, писал Коген, а Штамлер, в свою очередь, подчеркивал, что «идея права» (Rechtsidee) предоставляет особенный регулятивный принцип, на которое общественное движение должно ориентироваться. «По сути, неокантианцы прямо-таки заменили практический разум Канта «юридическим мировоззрением». Таким образом, они стали заложниками норм и законов общества, и у них отсутствовала та смелость, которую проявляет Субъективность, суверенно регулируя законы» [1. С. 8].

Кант совершил коперниканский переворот в философии, где субъект в субъект-объектных отношениях приобрел существенную роль, да и сам Кант придерживался достижений французской революции, где субъективность именно в конкретной революционной практике имела право на свое проявление. 
Однако не совсем верно, что неокантианцы основывали свои теории лишь на подобострастном чтении законов. На этот счет имеет место множество разных исследований. Например, современный философ Шварцчайлд далее интерпретирует «идею права» Марбургской школы так: где в то время как доктрина чистых, универсальных законов делает возможным последовательную теорию понятия о человечестве, Коген полагает, что законы любого реального положения будут далеки от идеальной формы чистого закона. Он утверждает, что государства в ходе их развития имеют тенденцию исправлять свои законы, чтобы лучше приблизиться к идеальным законам. Коген не утверждает, что история так или иначе вынуждена указать нам этот прогресс [2. С. 37]. Скорее, он просто принимает его как данную величину истории: философия более не может отрицать этот прогресс, чем это может отрицать прогресс истории физики и математики. В то же самое время оптимизм Когена был умерен пониманием несправедливости в неидеальном мире: моральный прогресс должен быть бесконечнымо потому, что никакое реальное положение никогда не будет воплощать идеал полностью [3. С. 139-40]. В терминах Когена, это есть непреодолимый промежуток между тем, что «есть», и тем, что «должно быть» (Being and Ought).

Коген известен умеренностью взглядов на глобальные революции в обществе, тем не менее он совсем не исключал их в случае, если «прогнившее» насквозь общество с его бюрократическим аппаратом не может и не хочет менять законы под нравственно-моральным давлением общества в поиске исправления социальной несправедливости. Роль субъекта у него нисколько не приуменьшается. Коген лишь хочет любым путем избежать «неизбежного» насилия, так как в ходе революций субъект растворяется в поисках цели истории.

Однако хочется вспомнить Сократа, который мог, сбежав из заключения, избежать смерти, уготовленной ему афинскими политиками. Однако он выпил цикуту с ядом, ибо хотел показать, что закон имеет приоритетное значение, даже если и не всегда справедлив.

Поскольку Коген видел это, политический прогресс был и должен двигать демократический социализм. «Все-таки законы недемократического государства не могут действительно урегулировать завещания и множества людей, даже если у государства есть власть над управлением их поведением», - так Коген заявлял в своем эссе 1904 года «Всеобщее, Равноправное, и Прямое Голосование права» (The General, Equal, and Direct Right Vote), «любое государство, законы которого составляют завещания людей, и множества связанных между собой должны иметь один всеобщий закон с универсальным избирательным правом [8. С. 215]. Более того, Коген утверждал, что, поскольку государства вносят изменения в свои законы, больше подходящие для идеальных законов, нормативно-правовая база этого государства должна исходить из управления хозяйственной деятельностью демократически образованными множествами людей. Другими словами, он считал, что идеальное государство позволит демократическим коллективам рабочих владеть средствами производства. В своей этике чистой воли, а также в его (1896) «Постскриптуме» к истории Ф.А. Ланге о материализме Коген утверждает, что этот социализм непосредственно следует из правильного понима- 
ния категорического императива Канта [2. С. 320]. У Когена отношение к людям не как к средству (для достижения цели) предполагает не эксплуатацию их труда, а скорее «кооперацию» рабочих и владельцев. Наряду с Ланге, таким образом, Коген ассоциирует социализм с кантианской, а не с марксистской точкой зрения. Кантианский социализм Когена имел важное влияние на политических лидеров социализма, таких как Эдуард, Бернштейн [2].

Мечта Маркса об обществе по «ту сторону права» (справедливость) и чувстве долга связана с другой мечтой, в которой распределение товаров больше происходит не в рамках рыночных механизмов, а политические и правовые государства отмирают. Коген, конечно, весьма критичен к этой точке зрения, утверждая, что «нет свободы без права и никакой свободной личности без общества, основанного на законах» (Critical Epilogue, p. 294-295) [4. C. 254]. Коген считает, что примирение между людьми и (внутренней) природой и нравственностью является бесконечной задачей, в то время как Маркс, кажется, видел свой идеал в том, что при определенных экономических условиях социальные проблемы, а также индивидуальные дилеммы исчезнут.

Карлу Форландеру, пытавшемуся балансировать между левыми и правыми социалистами, пришлось с горечью заявить, что положение все же стало черно-белым: либо Кант, либо Маркс. Меринг и особенно Плеханов пытались обосновать то, что материалист Спиноза подходит даже лучше Канта в качестве философского прародителя марксизма [1. С. 5].

Стоит упомянуть также таких классиков, как Рудольф Штамлер с его произведением Wirtschaft und Recht nach der materialistischen Geschichtsauffassung (1896) («Экономика и право в понимании исторического материализма»), в котором он признает, что исторический материализм - самый лучший из методов для проведения экономико-правовых исследований, и хочет дополнить его телеологическим, или целеполагающим, способом познания. По его мнению, лишь такое исследование приведёт неизбежно выросшие из общественных условий потребности к конечной цели, при которой «каждый делает чужие объективно заверенные правом цели своими» [6] Еще один известный философ Франц Штаудингер (1849-1921) в своей Ethic und Politik (1899) и изданном позже Wirtschaftlichen Grundlanden der Moral («Экономические предпосылки для нравственности») и др. также стоит на позициях марксистской этики, но пытается доказать, что для достижения высшей цели необходимо внедрение методики кантианской этики. Формальная этика (кантианская), в свою очередь, нуждается для обоснования своего осуществления и существования реальных знаний о законах экономики, возможность которой, в свою очередь, может предоставить марксизм», пишет о них Карл Форландер [6. С. 21].

\section{II. Маркс и нравственность}

Основные тенденции связи неокантианства с марксизмом повторяются у многих комментаторов и интерпретаторов, основанные в основном на трудах Когена, Бернштейна, Форландера, Ланге, Шмидта и др. Однако не так давно вышла книга Харри Ван Дер Линдена, который тоже, нам думается, 
придерживается этого «крыла»: в «Кантианской этике и социализме» от 1985 г., в которой он подробно описывает этический социализм, и в одной из глав, «Маркс и Нравственность: кантианский анализ и критика», проводит некоторое сопоставление, в котором он доказывает, почему марксистская теория может быть исправлена. Делая своей основой кантианскую социалистическую этику, он ищет сходства в обеих теориях. Ван Дер Линден хочет показать, что гегелевские рамки Маркса «должны» компенсироваться более «кантианской» ориентацией на идею исторического прогресса и ее актуальностью для социального действия. В основном он базируется на взглядах Когена и, собственно, реинтерпретирует и раскрывает их, в конечном счете, именно Когена и можно считать самым ярким представителем «этического социализма».

Отправная точка «их» социиализма выражена в следующем предложении: «Поступай таким образом, при котором ваше бытие согласовано с бытием кого-либо еще, всегда как цель, никогда просто как средство». В этих словах, говорит Коген, «самое глубокое и сильное значение категорического императива выражено в следующем: они содержат моральную программу нашего времени и всей будущей всемирной истории» [5]. И от этого до социализма он, кажется, вкладывает небольшое расстояние. «Идея предпочтения цели человечества становится преобразованной в идею социализма и определением каждого человека как абсолютной цели, цели самой по себе» [5. С. 303].

Поскольку существование общества только возможно, если каждый, живущий х собственной жизнью, в то же самое время помогает жить и другим, если каждый человек - одновременно средство и цель; если благосостояние каждого человека - одновременно условие, необходимое для благосостояния других, очевидно, что контраст между мной и вами, средствами и целями будет автоматически преодолен. Это, в конце концов, сравнение биологического организма, как предполагается, заставляет нас воспринимать (других). В органической структуре никакие части не должны быть расценены только как средства и ни одни только как цели. Согласно Канту, «организм - существо, в котором все цель и взаимно также и средство» [7. С. 622]. Теперь Кант был полностью знаком с природой органического, но он не видел - и в этом он отстал далеко от великих социологов, которые были его современниками, - что человеческое общество сформировано по тому же самому принципу [8].

Специальный аргумент Когена за отмену частной собственности показывает мрак, в котором он все еще трудится относительно этой фундаментальной проблемы общественной жизни. «У вещей, - говорит он, - есть ценность. У людей, однако, нет ценности - у них есть достоинство (Курсив наш. - П.К.). Рыночная цена ценности труда несовместима с достоинством человека» [5. С. 104]. Это подводит нас к пропасти «Марксистской фразеологии» и доктрине «товарного характера» труда и его объективизации.

Достоинство есть именно метафизическая величина, которое не измерить никакими материальными отношениями, оно не стоит в ряду с экономическими формациями - оно может быть потеряно как в «коммунистическом» обществе, так и обществе потребления. 


\section{III. «Гегельянско-марксистская ошибка»}

То, что Маркс видел коммунистические ценности не как бесконечную моральную задачу, а как спонтанное выражение коммунистического начала человеческой природы, является пунктом разногласий между Марксом и кантианскими этическими социалистами, которые показывают, что необходима коренная реконструкция взглядов Маркса и что они должны стать приемлемыми для социалистической теории и практики. Этот пункт разногласий является утверждением, что Марксу под преобразующей практикой капиталистического общества следовало бы рассматривать именно моральную практику.

Маркс утверждает, что мораль в ее различных функциях не имеет отношения к борьбе с социалистической/коммунистической идеологией, в то время как кантианские этические социалисты устанавливают эту борьбу в качестве моральной задачи. Отрицание Марксом морали является одним из аспектов его редукционизма, встроенного в его материалистическое понимание истории, но что особенно важно отметить, так это то, что эта концепция истории содержит четкое гегелевское догматическое метафизическое ядро, что «должное» рассматривается как неизбежно разворачивающееся в «бытии». «Я утверждаю, что эта точка зрения имманентна конфликту прогресса в критической морали, что она ведет к моральному «бесчувствию» по отношению к человеческим страданиям в прошлом и настоящем и что это призывает к репрессивным действиям во имя якобы неизбежной дороги к добру», - пишет Ван Дер Линден [4. С. 288].

В настоящее время основная суть критики Когена наиболее явно и полно изложена представителями франкфуртской школы, в частности в работах Хабермаса. Хабермас утверждает, что Маркс не смог увидеть, что человек как агент является одновременно инструментом решений и «символизирующим» животным, т.е. труд и язык являются фундаментальными антропологическими категориями, в том смысле, что никакие из этих категорий не могут быть сведень друг к другу. И Хабермас имеет в виду, что под «языком» понимается коммуникативное или интерактивное измерение человеческого существования, которое включает в себя моральные практики и критику отражения [4. С. 264].

По мнению Когена, роль морали в работе Маркса является «репрессированной», и одна из причин этого может быть и в том, что Маркс справедливо утверждал, что мораль функиии слишком часто является идеологической опорой для аморальных условий. Но Коген продолжает утверждать (что необходимое, однако, должно быть высказано), что «материалистическое понимание истории является логической ошибкой, и, поскольку вопрос заключается в моральной проблеме, это и есть моральная ошибка», заключает Линден, основываясь на таких трактатах Когена, как «Чистая воля» (Pure Will, p. 313).

И, собственно, он показывает существенное различие в понимании, как нужно двигаться к социализму и коммунизму как конечной цели, и то, что марксизм «должен быть» дополнен не гегельянским пониманием истории и ее способом развития, а кантианским. 
Ван Дер Линден приходит к тому, что «Марксистский корпус», может быть, в состоянии служить необходимой моральной основой для социалистической теории и практики, но он должен будет заменить его гегелевское философское понимание кантианской практической философией.

Как мы помним, Гегель утверждает, что молодой идеалист, поборник морали обрекает себя на иллюзию, что он и его нравственные идеалы могут быть судьей и инициатором социальных изменений, но на самом деле его борьба «покинута живым Духом». Чем старше и терпимей человек, тем он, наоборот, понимает, что история есть основание воплощения, а значит, что «История мира ... является судом мирового суда» [4. С. 358]. Маркс перенимает эту гегелевскую схему, но придает ей свой поворот. Парадигма сбитого с толку молодого человек больше не является лицом категорического императива с его «формальной правотой», но этические и социалисты-утописты с их абстрактными требованиями о справедливости и моральной гуманности.

Категорический императив, к которому тяготеют этические социалисты, противостоит любому неоправданному насилию и особенно террору. Это означает, что революционная борьба пролетариата не легитимна, потому что не согласуется с некоторыми философски обоснованными и прогнозируемыми идеалами, как утверждают неокантианские социалисты, а просто потому, что это лишь борьба пролетариата. Другими словами, практическое положение рабочего класса в историческом процессе легитимирует его существование и его борьбу [4. С. 266].

Все это соответствует в основном утверждениям Когена о том, что материалистическое понимание истории Маркса сводит практические идеи к теоретическим концепциям и этику - к логике и естествознанию, и в то же время «огненный этический дух» лежит в основе всех его сочинений.

И Коген не может не согласиться с заявлением Хабермаса, что «освобождение от голода и нищеты не обязательно коррелирует с освобождением от рабства и деградации, ибо нет никакой автоматически развивающейся связи между трудом и взаимодействием (коммуникацией)», подразумевая, что освобождение человека требует не только инструментальных и экономических усилий, но и его критического осмысления.

Большинство комментаторов Когена, и, конечно же, в частности, его оппоненты в лице ортодоксального марксизма обвиняли его в «буржуазном реформизме», восприняли его в качестве противника революции при любых обстоятельствах. Письменные доказательства опровергают эту интерпретацию. «Так же как и Кант, Коген выразил приверженность Французской революции и ее идеалам, и, более того, он заявляет, что «все реформы и эпохальные революция в религии, как и в политике, являются этическим идеализмом: реформы и революции являются периодами "экспериментальной этики"» (Pure Will, p. 328)» [4].

Однако Коген не уточняет, при каких обстоятельствах революции оправданны, но, основываясь на моем тезисе, он защищал ранее то, что революция оправданна, если не осталось других вариантов в противодействии систематическим репрессиям в условиях автономии, и это согласуется с его этикой», справедливо замечает Линден. 
Исходя из Когена, Коммунизм как telos (цель) истории разворачивается через отрицание существования правового государства, и отрицания отстаивают здесь возможность революции. Таким образом, диалектическое мышление, кажется, исключает возможность кардинального изменения через преобразующие шаги и призывает вместо этого к классовой поляризации и структурному насилию, независимо от эмпирических условий, в которых оно находится. Да, собственно, и само «неоправданное» насилие противоречит моральным принципам и категорическому императиву.

Таким образом, когеновская идея заключается в том, что не может быть никаких резких прорывов в нравственном прогрессе, а, скорее, нравственный идеал устанавливает бесконечную задачу по постепенной линии преобразований (капитализма). В соответствии с этим Коген противопоставляет «устойчивую перманентную революцию» «разрушительной революции», замечает Линден (Critical Epilogue, p. 294) [4. С. 282].

Мы можем также найти в Марксе экономический аналог кантианской идее, что моральный прогресс развивается на прагматическом уровне в пределах диалектики личного интереса. Прежде чем исследовать этот подход, несколько слов должно быть сказано о том, что кажется распространенным заблуждением и ошибкой некоторых марксистов (включая Маркса) относительно «предписывающей» (prescriptive) этики и ее значения. Мы отметили одно такое недоразумение и ошибку в требовании, что предписывающие законы (имеется в виду кантианская этика) в некотором смысле склонны к отчуждению, так как будто бы в них нет различия, которое не было бы описано между гетерономными и автономными законами.

«Связанная с этим проблема состоит в том, что такие понятия, как “обязанность контра интерес”, рассматриваются как типичные для буржуазного человека» и его моральной психологии, практический результат которой состоит в том, что моральные конфликты и дилеммы, связанные с практикой эмансипации, часто “заметены под ковер” спонтанной солидарности, коллективного сплава сознания в группу, и окончательного совпадения пролетарского интереса как интереса от имени человечества, и так далее» [9. С. 162].

Не без серьезного основания Маркс подчеркнул, что капитализм создает эгоизм, соревнование и индивидуализм. Но если это так, то усилия, чтобы преодолеть такие «склонности» через сотрудничество, солидарность и даже самопожертвование, являются моральными усилиями. Кроме того, борьба освободителя может привести к моральным конфликтам, как проиллюстрированный примером конфликт между обязанностью (материально) поддерживать семью и «обязанностью» присоединиться к забастовке [8].

Такие дилеммы и конфликты требуют морального отражения и, следовательно, предписывающих правил. Еще одна проблема в том, что марксистские критики предписывающей этики часто утверждают, что такая этика обязательно подразумевает абстрактное отрицание существующего положения дел, призыв к судье и человечеству в исторической пустоте. Это, конечно, важный аспект критического анализа Маркса этического и утопического социализма. Но кантианская этика социалистов отнюдь не отрицает того, что поиск посредничества между фактическим и идеалом важен, а также не 
отрицает, что моральная практика должна быть практикой, которая сообщает социальное, политическое и историческое знание, или, что есть материальные предпосылки для реализации и полного одобрения определенных норм и ценностей [4].

То, что кантианская этика социалистов, однако, действительно подчеркивает (и это - конечный пункт) - это то, что определенные моральные ценности, нормы и чувства возникают в пределах рабочего класса или экономической сферы, но не показывает ничего вообще об их обоснованности/законности. Если начать спорить, то, по-другому, это означает возвращение к так называемой гегельянско-марксистской ошибке и убеждению в том, что «должное неизбежно разворачивается в пределах того, "что должно быть", то есть того, что история - это судья и, по “счастливой случайности”, она (история) оказывается на стороне пролетариата» (Курсив мой. - П.К.). Мы должны сначала определить и объяснить, что есть "должное". Критическая этика логически приоритетна и независима от исторического развития, и такая этика - это предписывающая этика, которую, собственно, проповедует «этический социализм», замечает Линден в своем интересном труде [4. С. 248].

Теперь в конце мы хотим затронуть философию О.Г. Дробницкого, который ко всему прочему положительно оценивает кантовскую критику психологического детерминизма, его идею о внеэмпирическом, внепсихологическом характере морали. (Тогда как классовое сознание, защищаемое многими советскими философами, было буквально пронизано психологическим детерминизмом). Он исходит из того, что, с точки зрения Канта, мораль «не может быть тем, что побуждает человека психологически, что образует внутренний механизм его естественных склонностей и стремлений. Она, напротив, предписывает нечто человеку [...]. Нравственность, таким образом, это долженствование, обращенное к человеку, а не от природы заложенное в нем стремление или чувство» [10. С. 65]. Дробницкий соглашается с Кантом: психологический детерминизм означает отрицание свободы воли человека и его ответственности за свои поступки. Одну из альтернатив возникшей в истории этики проблемы он формулирует следующим образом: «Моральное побуждение есть обычная психическая причина действия, но тогда человек не способен управлять своим поведением и отвечать за свои поступки». Автор видит решение проблемы в признании того, что моральный мотив, долженствование, ставшее предметом сознания, - явление иного порядка, чем механизм психики, но действовать он может как побудитель поступка только через психический механизм. Противостояние мотива и психического побуждения на самом деле является соотношением двух разных плоскостей детерминации [10. С. 240]. Он считает, что тайна свободной воли не внутри механизмов человеческой психики, а в том способе, каким личность относится к общественной реальности: «Человек как сознательный и волящий субъект постоянно выходит за пределы внутренних механизмов собственной психики» [10. С. 240-241].

Видимо, причиной здесь послужило то, что он согласился с отрицательным отношением Канта к психологическому детерминизму, с точки зрения которого все поступки человека якобы предопределены, а поэтому свобода 
воли и ответственность человека невозможны. При этом автор отрицает психологический подход в принципе, даже если в нем учитывается социальная (вторая) природа человека. «Мораль, - пишет он, - внеприродная, общественно-историческая детерминанта человеческого действия, притом такая, что здесь даже концепт второй природы человека как конденсата его прошлого опыта оказывается не всегда достаточным и применимым» [11. С. 126].

О.Г. Дробницкий настаивает на том, что мораль - это какая-то внепсихологическая сила. В этом отношении весьма показательно следующее его утверждение: «Чувство личной ответственности, разумность воли, способность самозаконодательства и тому подобное отнюдь не являются заранее положенными качествами человека как такового, константами или параметрами его психики или мышления. [...] Таковые способности вменяются человеку нравственностью. Они образуются не внутренней структурой его сознания или его эмпирическим характером, природой (даже второй, социально сформировавшейся природой), а тем способом вменения, который составляет специфическую особенность морали» [10. С. 294]. В морали, конечно, имеет место диалектика внешнего и внутреннего, общественного и индивидуального, в силу которой индивидуальное сознание обогащается новым содержанием, воспринимает задачи, выдвигаемые общественной жизнью. Поскольку автор отделяет мораль от психологии, он рассматривает свободу воли не как психологическое явление, а как установление самой нравственности. «До Канта, - отмечает он, - свобода понималась как онтологическая или психологическая предпосылка нравственности, без которой последняя невозможна. Кант же подошел к пониманию того, что [...] свобода - явление самой нравственности» [10. С. 292]. Автору эта идея представляется важным вкладом в этику, и он придает ей в своей концепции морали существенное значение. «Свободная воля, - пишет он, - это феномен самой нравственности, порождение присущего ей специфического механизма детерминации человеческого действия» [10. С. 284].

И вновь мир пропитан идеями социализма - всемирный кризис показал неустойчивость как советской формы социализма, так и западного либерализма. К какому же строю двигаться? К левому (ортодоксальномарксистскому) или все же к так называемому этическому социализму или, по-другому, «умеренному», который стремится не к радикальной перестройке мира, а скорее к дополнению и разбавлению жесткого капитализма путем постепенного улучшения юридических законов и стремлению к «общественному благосостоянию» путем социализации.

\section{Лumepamypa}

1. Oittinen $V$. Bernstein ja Kantin varjo työväenliikkeen yllä. Bernstein-seminaari Helsingissä 6 . marraskuuta, 1999.

2. Cohen H. Ethik des reinen Willens. Berlin, 1904.

3. Schwarzschild S. "'Germanism and Judaism' - Hermann Cohen's Normative Paradigm of the German-Jewish Symbiosis," in D. Bronson (ed.), Jews and Germans from 1860 to 1933: The Problematic Symbiosis, Heidelberg: Carl Winter Universität, 1979.

4. Van Der Linden Harry. Kantian ethics and Socialism.Hacket Publishing Company. Indianapolis, 1988. 
5. Gay P. The Dilemma of Democratic Socialism: Eduard Bernstein's Challenge to Marx, New York, NY: Columbia University Press, 1970.

6. Vörlander K. Neuzeitliche Staats und Gesellschaftstheorien. Lpz, 1926.

7. Kant I. Kritik der Urteilskraft (The Critique of Judgment) (Works, Vol. VI), 1790.

8. Ludvig Van Mises Institute / [Электронный pecypc]. URL: http://mises.org/books/socialism/part4_ch30.aspx (дата обращения: 01.03.2014).

9. Skillen A. Workers's interest and Proletarian ethics // Marx and Morality. Suplementary volume VII of Canadian journal of Philosophy, 1981.

10. Дробницкий О. Г. Понятие морали. М.,1974.

11. Дробницкий О.Г. Философия Канта и современность. М.: Мысль, 1974.

Kurhinen Pavel Saint-Petersburg State University (Saint-Petersburg, Russian Federation). DOI 10.17223/1998863X/30/12

HUMAN DIGNITY, ETHICAL SOCIALISM AND SOVIET ETHICS

Keywords: Ethical Socialism, Moral and legal aspect of philosophy, Social practice, Categorical imperative and human dignity, Transcendental object.

The purpose of this article is to outline those essential distinctions of ethical socialism from a radical or left socialism, namely, not in the political plane, but in respect of development of "ethical" doctrines. Why the moral and legal aspect in philosophy of ethical socialism and as Kant's categorical imperative can enrich dialectic materialism, and also show why it is better to change social reality peacefully, instead of world revolutions, hat is so important. Proceeding from Cohen, Communism as telos (goal) of history unfolds through denying the existence of the rule of law and upholds the denial here of the possibility of revolution. Thus dialectical thinking seems to exclude the possibility of non-radical change through transformative steps of laws, and calls instead for a class polarization and structural violence, regardless of the empirical conditions where it is located. The very "unjustified" violence is contrary to moral principles and the categorical imperative. The categorical imperative, which dominates in thoughts of ethical socialists, is opposed to any unjustified violence and especially terror. This means that the revolutionary struggle of the proletariat is not legitimate because it is not consistent with some philosophical reasonable and predictable ideals, according to neo-Kantian socialists, but simply because It's only the struggle of the proletariat. In other words, the practical situation of the working class in the historical process legitimizes its existence and its struggle without any doubts. Habermas argues that Marx failed to see a person as an agent, which means the both a tool-making and "symbolizing" the animals, that is - labor and language are fundamental anthropological categories in the sense, that none of these categories cannot be reduced by one other. If you start to argue, then it means a return to the Hegelian - Marxist "error" and believe that "justice will inevitably turns to the extent that what should be", what history is - the judge and " happily appears" on the side of the proletariat. In our opinion we must first define and explain what is "proper" and truth, before class of proletariat could be justified. Critical ethics is logically prior and independent of historical development and such ethics prescribes that actually preaches "ethical socialism". The article also makes some parallels to universal prescriptivism of R.M. Soviet author Oleg Drobnicki which considers that they both tried in some sense to unify Kantian universalism, his main goal is not just changing concept of historical materialism, but to bring human dignity to agenda in Soviet ethics.

\section{References}

1. Oittinen, V. (1999) Bernstein ja Kantin varjo työväenliikkeen yllä. Bernstein-seminaari Helsingissä

6. marraskuuta.

2. Cohen, H. (1904) Ethik des reinen Willens. Berlin.

3. Schwarzschild, S. (1979) Germanism and Judaism - Hermann Cohen's Normative Paradigm of the German-Jewish Symbiosis. In: Bronson, D. (ed.) Jews and Germans from 1860 to 1933: The Problematic Symbiosis. Heidelberg: Carl Winter Universität.

4. Van Der Linden, H. (1988) Kantian ethics and Socialism. Indianapolis: Hacket Publishing Company.

5. Gay, P. (1970) The Dilemma of Democratic Socialism: Eduard Bernstein's Challenge to Marx, New York, NY: Columbia University Press. 
6. Vörlander, K. (1926) Neuzeitliche Staats und Gesellschaftstheorien. Leipsig.

7. Kant, I. (1790) Kritik der Urteilskraft (The Critique of Judgment) (Works, Vol. VI).

8. Ludvig Van Mises Institute. [Online] Available from: http://mises.org/books/socialism/part4_ch30.aspx. (Accessed: 1st March 2014).

9. Skillen, A. (1981) Workers's interest and Proletarian ethics. "Marx and Morality". Canadian Journal of Philosophy. Suplementary volume VII.

10. Drobnitskiy, O.G. (1974) Ponyatie morali [The Concept of Morality]. Moscow: Nauka.

11. Drobnitskiy, O.G. (1974) Filosofiya Kanta i sovremennost' [Kantian Philosophy and Modernity]. Moscow: Mysl'. 